\title{
A Hydrogen Leak Detection System for Aerospace and Commercial Applications
}

Gary W. Hunter

Lewis Research Center

Cleveland, Ohio

D.B. Makel, E.D. Jansa, G. Patterson, and P.J. Cova

GenCorp Aerojet

Sacramento, California

C.C. Liu and Q.H. Wu

Case Western Reserve University

Cleveland, Ohio

W.T. Powers

NASA George C. Marshall Space Flight Center

Marshall Space Flight Center, Alabama

Prepared for the

31st Joint Propulsion Conference and Exhibit cosponsored by AIAA, ASME, SAE, and ASEE San Diego, California, July 10-12, 1995
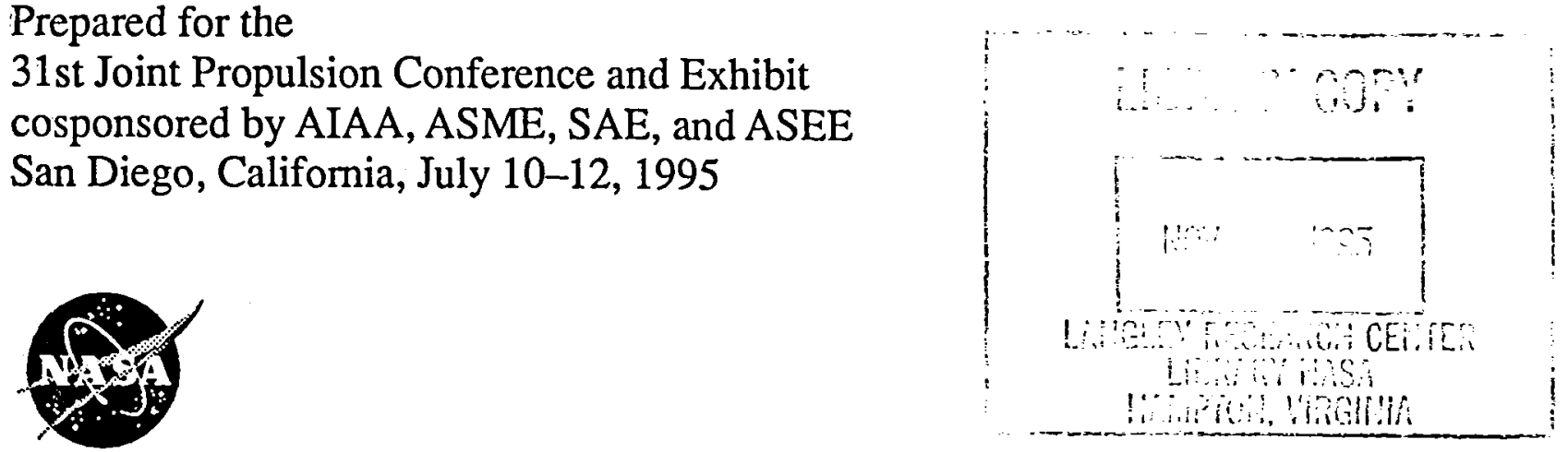

National Aeronautics and

Space Administration 


\title{
A HYDROGEN LEAK DETECTION SYSTEM FOR AEROSPACE AND COMMERCIAL APPLICATIONS
}

\author{
Gary W. Hunter \\ NASA Lewis Research Center \\ Cleveland, OH 44135
}

\author{
D. B. Makel, E. D. Jansa, G. Patterson and P. J. Cova \\ GenCorp Aerojet \\ Sacramento, CA 95813 \\ C. C. Liu and Q. H. Wu \\ Electronics Design Center \\ Case Western Reserve University \\ Cleveland, OH 44106 \\ W. T. Powers \\ NASA George C. Marshall Space Flight Center \\ Marshall Space Flight Center, AL 35812
}

\begin{abstract}
Leaks on the Space Shuttle while on the Launch Pad have generated interest in hydrogen leak monitoring technology. Microfabricated hydrogen sensors are being fabricated at Case Western Reserve University and tested at NASA Lewis Research Center. These sensors have been integrated into hardware and software designed by Aerojet and Marhsall Space Flight Center. This complete system allows for rapid, multipoint leak monitoring. The monitoring system processes data from the hydrogen sensors and presents the operator with a visual indication of the leak location and magnitude. Although the leak monitoring system was designed for hydrogen propulsion systems, the possible applications of this monitoring system are wide ranged. This system is in operation in an automotive application which requires high sensitivity to hydrogen.
\end{abstract}

\section{INTRODUCTION}

In the aerospace industry, hydrogen propellant leaks pose significant operational problems. Safety concerns mandate the detection of hydrogen leaks in a wide range of environments including environments where traditional commercial hydrogen sensors are inoperative. Display of the detected leak's location and magnitude is crucial in determining the severity of the safety problem and the proper response. If the leak location and magnitude cannot be located in a timely manner, the consequences range from expensive delays to potential loss of life and equipment. For example, leaks on the Space Shuttle while on the launch pad temporarily grounded the fleet in 1990 until the leak source could be identified. These delays in scheduled launches were a significant expense to the Shuttle program.

In response to the hydrogen leak problem, several initiatives have been undertaken by NASA to improve propellant leak detection capabilities during assembly, pre-launch operations, and night. The objective has been to reduce the operational cost of assembling and maintaining hydrogen delivery systems with automated detection systems. In particular, efforts were made to develop an automated hydrogen leak detection system using microfabricated point-contact hydrogen sensors.

The development of such an automated hydrogen detection system requires both dependable hydrogen sensors and the hardware and software to 
monitor the hydrogen sensors. Efforts have progressed on two fronts. NASA Lewis Research Center (LeRC), in conjunction with Case Western Reserve University (CWRU), is developing point-contact hydrogen sensors. These sensors are microfabricated to minimize power consumption and allow placement of the sensors in a wide variety of locations. In a separate contract with Marshall Space Flight Center (MSFC), Gencorp Aerojet (Aerojet) is developing an automated hydrogen leak detection system that monitors microfabricated point-contact hydrogen sensors and visually displays the source and magnitude of a leak. The combined effort of these two programs is a complete system that can monitor leaks in hydrogen propulsion systems.

The complete system consists of three elements: a sensor array, a signal processing unit, and a diagnostic processor. The sensor array consists of discrete microfabricated hydrogen sensors which are located in potential leak sites. The signal processing unit provides power to the sensors, and analog to digital data conversion of the sensor outputs. The diagnostic processor analyzes the sensor outputs to determine leak source positions and magnitude. Leak data from the sensor network is interpreted using knowledg-based software and displayed on-line through a graphical user interface.

Hydrogen propulsion system monitoring is not the only application that could make use of a leak detection system. The monitoring system described in this paper could be used with any vehicle or facil- . ity using gaseous hydrogen. Aerojet has developed a commercial system using the NASA LeRC and CWRU sensors. This commercial system allows for rapid, multipoint leak checking of the high pressure fuel systems of natural gas vehicles by using hydrogen as a trace gas. This system is currently in use by Ford Motor Company for assembly line leak checking of natural gas vehicles.

The purpose of this paper is to discuss the development of the hydrogen leak detection system. The first section will discuss the development of microfabricated hydrogen sensors at NASA LeRC and CWRU. The second section will discuss the hardware, sensor integration, and software in the Aerojet system. The third section will discuss the prototype flight multiplexing system developed at Aerojet. The final section discusses the first commercial product: a trace hydrogen gas detec- tion system for leak checking natural gas vehicles. It is demonstrated that this effort represents signiffcant interaction between NASA, industry, and academia.

\section{HYDROGEN SENSORS DEVELOPMENT}

Hydrogen sensor development is a collaborative effort between NASA LeRC and CWRU. The sensors were fabricated at $C W R U$ and characterized at NASA LeRC. The results of this characterization affected future sensor fabrication procedure. Through this collaboration between government and academia, an improved sensor design has been developed. The following discusses the NASA LeRC Hydrogen Sensor Testing System used to characterize the sensors, and the hydrogen sensor design and characterization.

\section{Hydrogen Sensor Testing System}

The facility used for sensor testing at NASA LeRC is shown schematically in Figure 1. The facility can supply a continuous flow of gaseous hydrogen $\left(\mathrm{H}_{2}\right)$, helium $(\mathrm{He})$, nitrogen $\left(\mathrm{N}_{2}\right)$, or air, either individually or as a mixture, to a chamber containing the sensor under test. The temperature $(T)$ and pressure $(P)$ of the gas are measured as the gas enters the test chamber. The composition of the gas is monitored by a mass spectrometer. The gas leaves the test chamber and is sent through a flame before being vented.

Computer-controlled mass flow controllers accurately control gas flow into the test chamber. The helium, nitrogen, and air mass flow controllers are calibrated for flows from 0 to 1000 standard cubic centimeters per minute (sccm). One hydrogen mass flow controller operates in the range from 0 to $20 \mathrm{sccm}$ and a separate hydrogen flow controller operates from 20 to $1000 \mathrm{sccm}$. A three-way valve allows the gas to bypass the test chamber and go directly to the vent. This feature allows the mass flow controllers to be stabilized without flowing gases through the test chamber.

The mass flow controllers can also flow gases for which they are not calibrated. Thus, a given gas can be flowed through more than one mass flow controller to increase the overall flow rate of that gas. Further, gas mixtures such as $1 \%$ hydrogen in 
nitrogen can also be used. Determination of the true flow rate when flowing alternate gases through a given mass flow controller is obtained by using manufacturer provided conversion factors. This system allows a wide range of hydrogen containing mixtures to be sent through the test chamber at a wide range of flow rates. The test chamber is designed for testing of several sensors which are mounted on DIP connectors. The incoming gas is injected onto the sample surface by means of a tube conducting the gas into the chamber.

The mass spectrometer provides an independent measure of the relative concentration of the gases in the test cells as a function of time. This information, accounting for the time delay inherent in the mass spectrometer reading, has been used to determine the amount of time for changes in the flow composition to reach a steady state value in the test chamber. The time it takes to reach steady state affects the corresponding measured response and recovery times of the sensor. On the basis of this information, testing procedures sought to maximize the flow rate and thereby minimize the time for the test chamber to reach steady state. Thus, the total flow rates are maximized within the constraints of the available gases and mass now controllers. The fow rates for the tests at NASA LeRC were $1500 \mathrm{sccm}$. Under these conditions, the time for steady state in the test chamber is usually less than a minute.

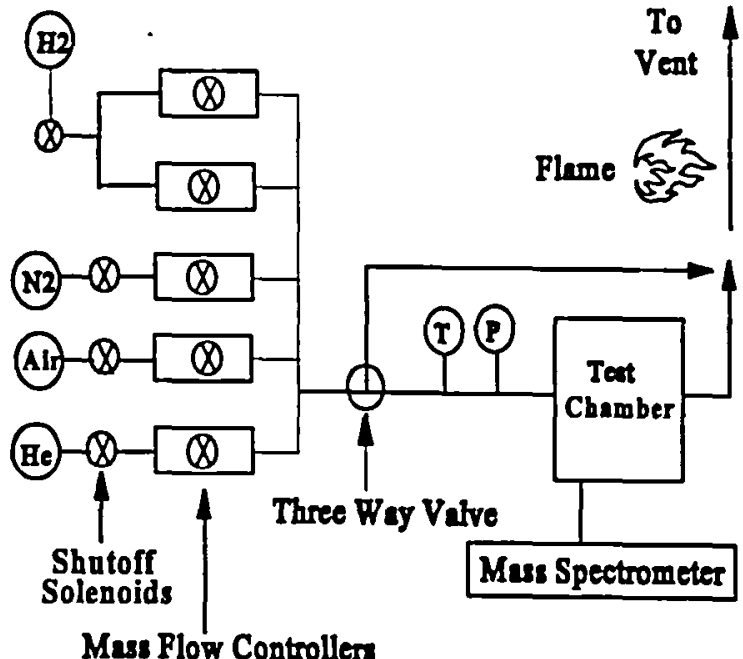

Figure 1. Schematic diagram of the NASA LeRC $\mathrm{H}_{2}$ sensor testing facility. $T$ and $P$ represent temperature and pressure measurements.

\section{Hydrogen Sensor Fabrication and Characterization}

The development of microfabricated hydrogen sensors was necessary since hydrogen sensors that meet the needs of aerospace applications did not exist. ${ }^{1-2}$ One component of the sensor development program at NASA LeRC involves the fabrication at CWRU of palladium-silver (PdAg) Schottky diodes on silicon (Si) substrates. This type of sensor is based on metal-oxide-semiconductor (MOS) technology such as that used in the semiconductor electronics industry. The gas sensing MOS structures are composed of a hydrogen sensitive metal deposited on an insulator adherent to a semiconductor. This forms a Schottky diode in the case of a very thin layer of insulator. The most common MOS structure used for hydrogen detection is the $\mathrm{Pd}_{-} \mathrm{SiO}_{2}$-Si structure. Hydrogen dissociates on the Pd surface and diffuses to the Pd$\mathrm{SiO}_{2}$ interface affecting the electronic properties of the MOS system. ${ }^{3}$ The use of pure Pd as the hydrogen sensitive metal is problematic for several reasons. The most serious of these involves a phase change that occurs at high hydrogen concentrations which can lead to hysteresis or film damage.

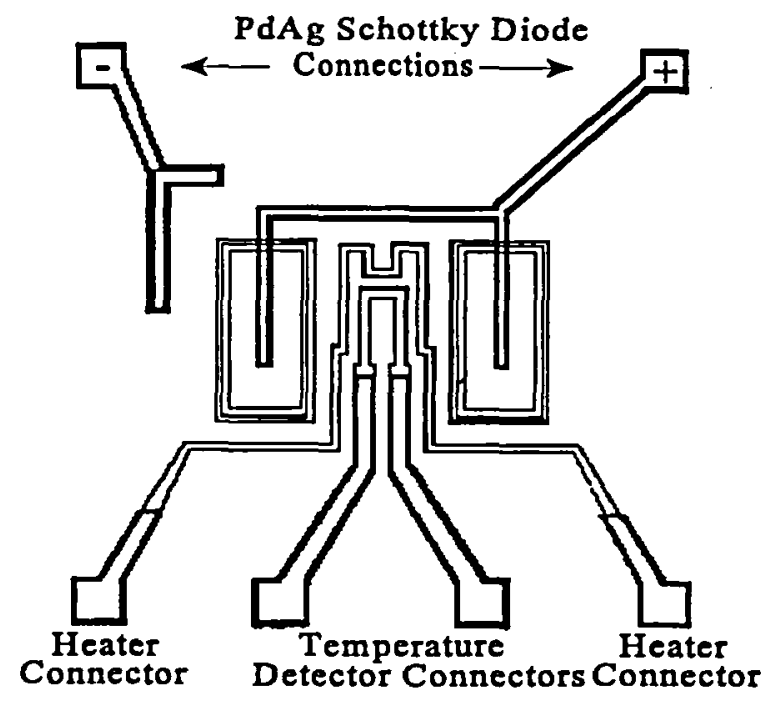

Figure 2. Schematic diagram of the Pd13\%Ag Schottky Diode Hydrogen Sensor. The Pd13\%Ag Schottky diode resides symmetrically on either side of a heater and temperature detector.

Schottky diodes using Pd13\%Ag as the hydrogen sensitive metal are presently being 
fabricated. The use of PdAg in hydrogen sensing applications was pioneered by Hughes.' Palladium silver has advantages over Pd. Palladium silver is more resistant to damage from exposure to high hydrogen concentrations than Pd. Furthermore, the alloy has faster response times than Pd. The 13\% Ag concentration is the optimum concentration for balancing these improved properties and the need to have a large enough $P d$ concentration to allow sensitivity to hydrogen. ${ }^{5}$

The sensor structure is shown in Figure 2. The structure includes a Pd13\%Ag Schottky diode, a temperature detector, and a heater all incorporated in the same chip. The sensor is fabricated using a $\mathrm{n}$ type silicon wafer on which approximately $50 \AA$ of $\mathrm{SiO}_{2}$ is thermally grown in the sensor region. The heater and temperature detector are platinum covered with $\mathrm{SiO}_{2}$. Gold leads are applied by thermal compression bonding and the sensor is mounted on a TO5 header or on a ceramic flat package. The surface area of the Schottky diode is $6.1 \times 10^{-3} \mathrm{~cm}^{2}$.

The response of the Schottky diodes was determined by measuring the diode's reverse current. Five volts were placed across a circuit composed of the diode and a separate resistor in series. The reverse current was determined by measuring the voltage drop across the resistor. The sensor temperature was measured by monitoring in a Wheatstone bridge the resistance of the temperature detector.

The time response of a typical Pd13\%Ag Schottky diode sensor at a sensor temperature of $45^{\circ} \mathrm{C}$ to $0.2 \%$ hydrogen is shown in Figure 3 . Two different experiments using two different carrier gases are shown: either pure nitrogen or a mixture of $90 \% \mathrm{~N}_{2}$ and $10 \% \mathrm{O}_{2}$. The sensor is first exposed to the carrier gas for 10 minutes, then to $0.2 \% \mathrm{H}_{2}$ in the carrier gas, then the carrier gas. This is done for 4 cycles. After the last exposure to hydrogen, the nitrogen carrier gas is changed to the $90 \%$ $\mathrm{N}_{2}: 10 \% \mathrm{O}_{2}$ mixture.

Several features of the sensor behavior should be noted. First, the sensor is highly sensitive to hydrogen with a rapid response to hydrogen introduction in either an inert or an oxygen containing carrier gas. The reverse current increases by nearly a factor of 1000 when the sensor is exposed to hydrogen, from on the order of $0.1 \mu \mathrm{A}$ to on the order $100 \mu \mathrm{A}$. The measured response time is chamber dependent. Our data suggests the response time under these conditions is less than 45 seconds to reach $90 \%$ of the final value.

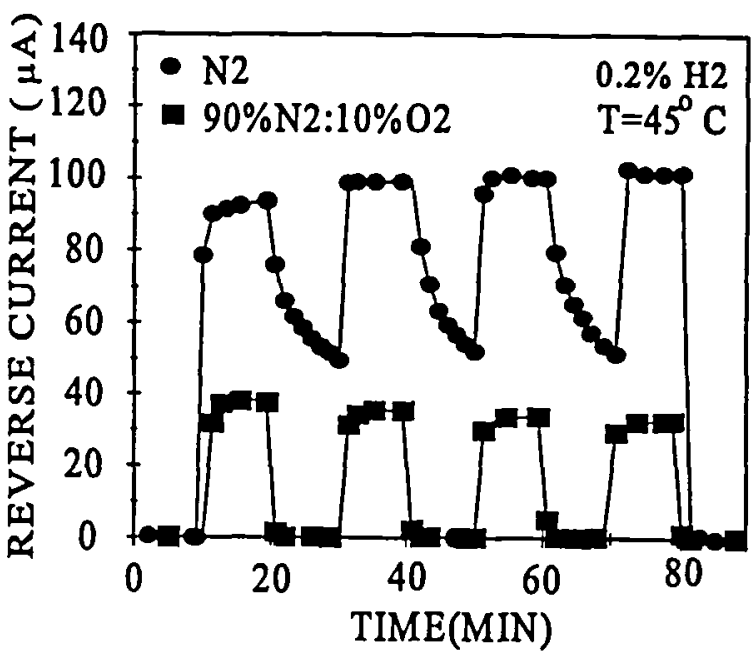

Figure 3. The time response of a Pd13\% Ag Schottky diode hydrogen sensor to cycling to $0.2 \%$ hydrogen in $\mathrm{N}_{2}$ and $90 \% \mathrm{~N}_{2}$ and $10 \% \mathrm{O}_{2}$. The large and rapid response of the sensor and the effect of oxygen is evident.

Secondly, the presence of oxygen significantly affects the sensor behavior. The sensor response to nitrogen is more than a factor of two larger than that in nitrogen and oxygen. The presence of oxygen also impacts the recovery time. The recovery time to $90 \%$ of the baseline value in nitrogen and oxygen is on the order of seconds, while the recovery time in pure nitrogen is on the order of many minutes. However, when the carrier gas is changed from nitrogen to the nitrogen and oxygen mixture at time equal to 80 minutes in Figure 3, the sensor recovers with approximately the same speed as found when the carrier gas contains oxygen.

Thirdly, Figure 3 demonstrates the repeatability of the sensor response. For each exposure to hydrogen, the reverse current increases to within $13 \%$ of the same value. It should be noted that this $13 \%$ variation is out of a total change of nearly a factor of $\mathbf{1 0 0 0}$ for both gas mixtures. Further, even the pattern of the slow recovery in nitrogen is repeatable. 
The response of the sensor to varying temperatures and hydrogen concentrations in a $90 \% \mathrm{~N}_{2}: 10 \% \mathrm{O}_{2}$ carrier gas is shown in Figure 4. The sensor temperatures tested were $45^{\circ} \mathrm{C}, 60^{\circ} \mathrm{C}$, $80^{\circ} \mathrm{C}$, and $100^{\circ} \mathrm{C}$. The sensor was first exposed to the carrier gas for 10 minutes, then, for 10 minutes each, $100 \mathrm{ppm}, 500 \mathrm{ppm}, 1000 \mathrm{ppm}$, and $5000 \mathrm{ppm}$ $\mathrm{H}_{2}$ in the carrier gas. The hydrogen flow was then stopped and the sensor recovered towards the baseline in the carrier gas. Figure 4 shows the sensor response on a linear scale, while the inset shows the first 30 minutes of the same test on a Iogarithmic scale.

The first sensor characteristic demonstrated by Figure $\mathbf{4}$ concerns the magnitude of the response of the diode throughout the temperature and hydrogen concentration range. After a response of nearly an order of magnitude to $100 \mathrm{ppm} \mathrm{H}_{2}$ (Figure 4 inset), the sensor responds by a factor of nearly 100 to the subsequent factor of $\mathbf{5 0}$ change in the hydrogen concentration (Figure 4). Therefore, the sensor reverse current responds to changes in hydrogen concentration throughout the hydrogen concentration range from $100 \mathrm{ppm}$ to $5000 \mathrm{ppm}$ in air and for sensor temperatures below $100^{\circ} \mathrm{C}$.
Secondly, the magnitude of the response and the time it takes for the sensor to reach a stable value is temperature dependent. The higher the temperature, the larger the reverse current and the shorter the time until the reverse current stabilizes. However, the sensor response at $100^{\circ} \mathrm{C}$ and 5000 ppm hydrogen concentration is different from that at other temperatures. The reverse current reaches a maximum almost immediately upon the change from $1000 \mathrm{ppm}$ to $5000 \mathrm{ppm}$ hydrogen, then decreases with continued hydrogen exposure. This high concentration/high temperature behavior is explored further elsewhere."

Subsequent results suggest that the response of the sensor to higher temperatures with higher hydrogen concentrations may likely be due to a phase change in the Pd13\%Ag. These results will not be discussed in detail here due to space limitation. However, although Pd13\%Ag is more resistance to damage than $\mathrm{Pd}$, these results suggest that a phase change does occur in the Pd13\%Ag. The diode and the Pd13\%Ag often survive this possible phase change, but the sensor properties may be changed.

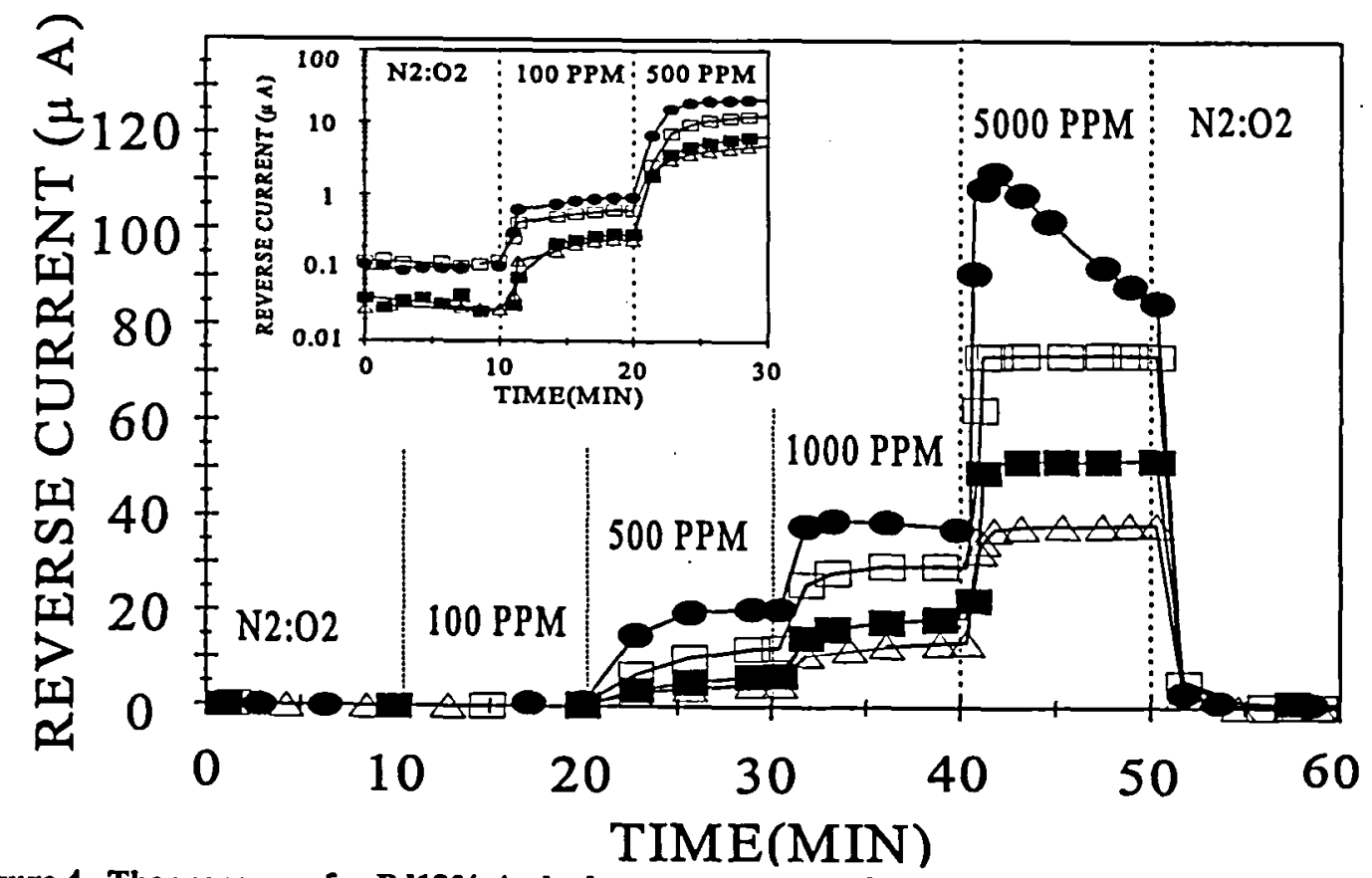

Figure 4. The response of a $\mathrm{Pd} 13 \%$ Ag hydrogen sensor as a function of temperature when exposed for 10 minutes to the carrier gas $90 \% \mathrm{~N}_{2}: 10 \% \mathrm{O}_{2}$, and then for 10 minutes each to $100 \mathrm{ppm}, 500 \mathrm{ppm}, 1000$ $\mathrm{ppm}$, and $5000 \mathrm{ppm}$ of $\mathrm{H}_{2}$ in the carrier gas. The inset shows the carrier gas, $100 \mathrm{ppm}$ and $500 \mathrm{ppm} \mathrm{of} \mathrm{H}_{2}$ response in a logarithmic scale. The temperatures are $45^{\circ} \mathrm{C}(\Delta), 60^{\circ} \mathrm{C}(\square), 80^{\circ} \mathrm{C}(\square)$, and $100^{\circ} \mathrm{C}(\theta)$. 
Therefore, the properties of the Pd13\%Ag sensor make it very useful for applications where sensing small amounts of hydrogen is necessary. The sensor response is large, rapid, and repeatable. If quick recovery is necessary, then the sensor should be operated in oxygen containing gases. If detection of the presence of hydrogen is required without rapid recovery, then this sensor can also be used in inert environments. The sensor responds to hydrogen across a wide concentration range with a signal and response time that is temperature dependent. This sensor can be used to monitor leaks in a multipoint leak detection scheme involving a number of these sensors. The design of the Aerojet produced system to monitor these and possibly other sensors follows in the next section.

\section{MULTIPOINT LEAK DETECTION MONITORING}

In order to gain information from a large number of the sensors in actual field applications, hardware and software must be available to operate the sensors and interpret the incoming data. The sensor support structure design must take into account the needs of aerospace applications. For example, the amount of wiring and power used to operate the sensors must be kept at a minimum. The signal from the sensors must be processed and displayed by the hardware and software in such a manner so as to be useful to the operator. Aerojet has been actively involved in developing such a system. The goal of the automated hydrogen propellant leak detection system is to provide leak source and magnitude information in real time. The following subsection presents the system hardware design and sensor integration. The second subsection discusses the leak detection software and algorithms.

\section{Hardware Design and Sensor Integration}

The major design features of the automated hydrogen propellant leak detection system are illustrated in Figure 5. The hydrogen sensors provide electrical signals that indicate the local hydrogen partial pressure. These sensors are distributed throughout the propulsion system fuel tanks, feedlines, and engine elements. Individual sensors, characterized as site sensors, are located at high probability leak sources such as flanges, instrumentation ports or in areas with limited physical or visual access. Other sensors are mounted throughout the engine and fowline compartments providing zone-imaging data serving as safety monitors.

A distributed array leak detection system

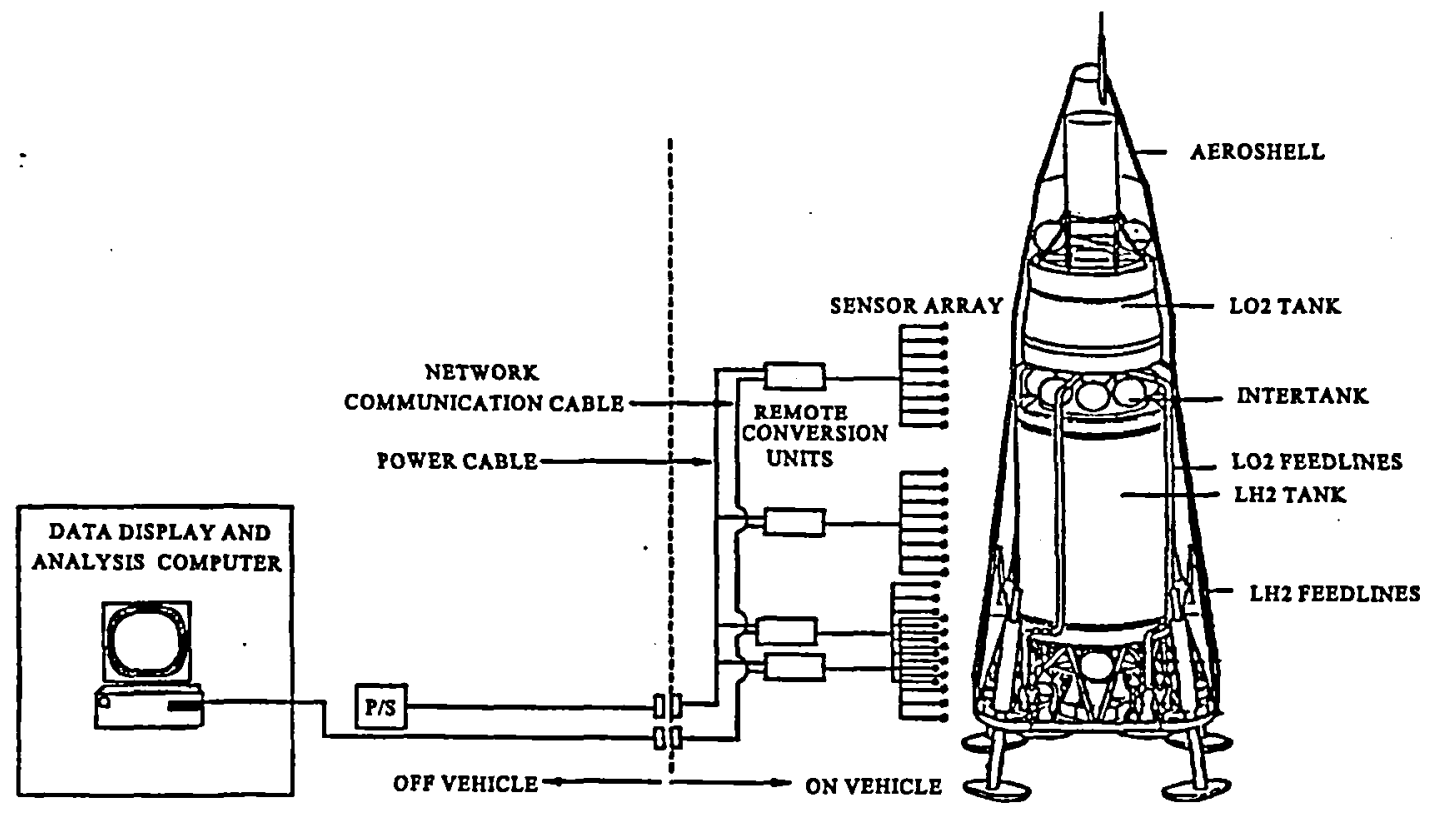

Figure 5. Schematic of Automated Leak Detection System for Propulsion Systems. The system monitors hydrogen leaks at points of interest throughout the vehicle using hydrogen sensors monitored by advanced hardware and software. 
requires connecting and gathering information from a large number of sensors. Mounting a large number of point sensors throughout the leak susceptible area poses a significant cabling challenge. Each device must be provided with connections for heating power, device bias voltages, temperature sensing, and one or more hydrogen sensors. The cost of cabling to a large number of active sensor elements that a practical system would employ is reduced by multiplexing a string of sensors into a single cable, terminating several cables at each distributed signal processor, and connecting the signal processors with the ground data processor through a single serial bus. Making use of the increasing integration that the electronics industry is providing in monolithic microcontrollers, the signal processor units are expected to be small units mounted in proximity to the sensors throughout the vehicle and launch pad fuel delivery systems. The distributed signal processors collect, process, and record the sensor measurements. Once the data is collected, it is serialized and transmitted to a ground-based data processor where the leak detection algorithms are executed.

The degree to which the leak detection system can successfully identify and characterize leaks depends on how reliably the instantaneous local hydrogen content can be inferred from the point hydrogen sensor signals. Device to device variations and saturation level must be considered. In order to characterize the behavior of a number of sensors in a multiplexing scheme, several sensors were tested. Figure 6 shows time plots of the reverse biased diode currents for eight multiplexed sensors responding to and recovering from exposure to various hydrogen/nitrogen mixtures. The testing was done at Aerojet in a smaller test chamber than the LeRC system but with flow control similar to that seen in Figure 1. The measurement in Figure 6 is the output signal after signal conditioning. The measurements show that the characteristic responses times of these devices are less than 10 seconds. The steady state level of response corresponds to the hydrogen concentration at exposure except when saturation occurs which is approximately $1 \%$ hydrogen.

Figure 7 shows typical calibration cross plots derived from the data shown in Figure 6. The value of the measurement at $1000 \mathrm{ppm}$ hydrogen in nitrogen is set to 1 and all other measurements are

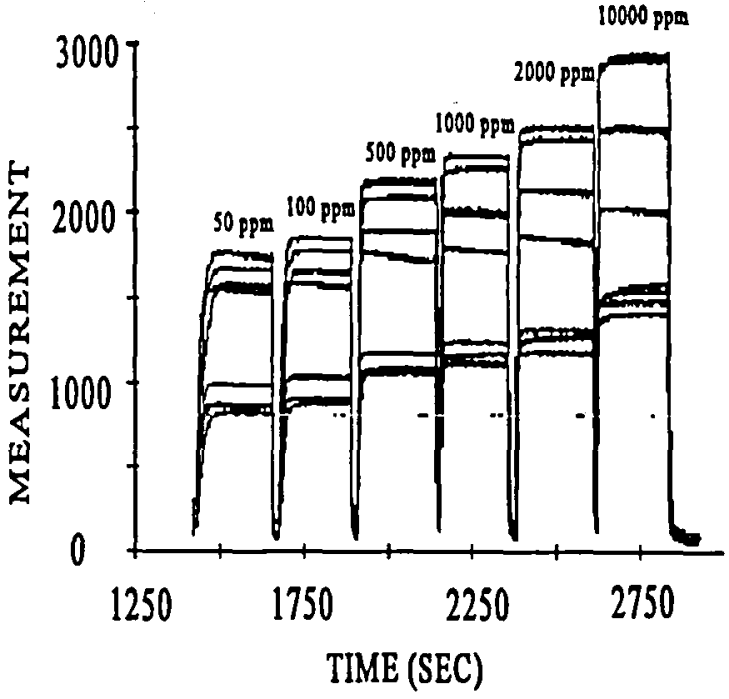

Figure 6. Characteristic step response of the 8 multiplexed hydrogen sensors in a multiplexed system. The measurement is the response of the sensor after signal conditioning. The gas flow is hydrogen in nitrogen and the sensor temperature is $60^{\circ} \mathrm{C}$.

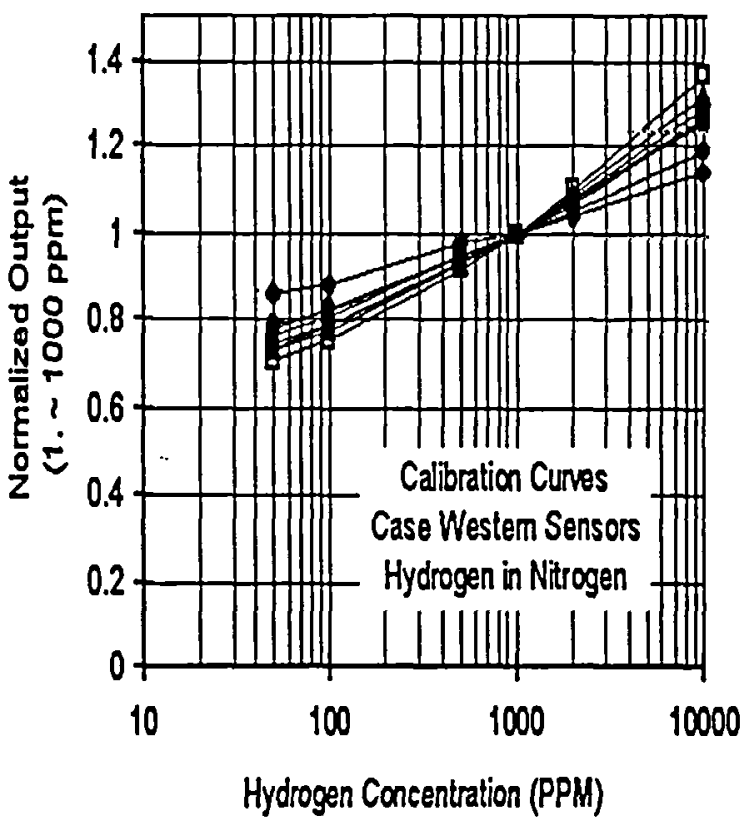

Figure 7. Calibration curves for eight diode sensors. The measured output is normalized so that the response at $1000 \mathrm{ppm}$ hydrogen in nitrogen is set to 1 and all other values are scaled accordingly. The figure shows the similarity in calibration curves for all sensors tested. 


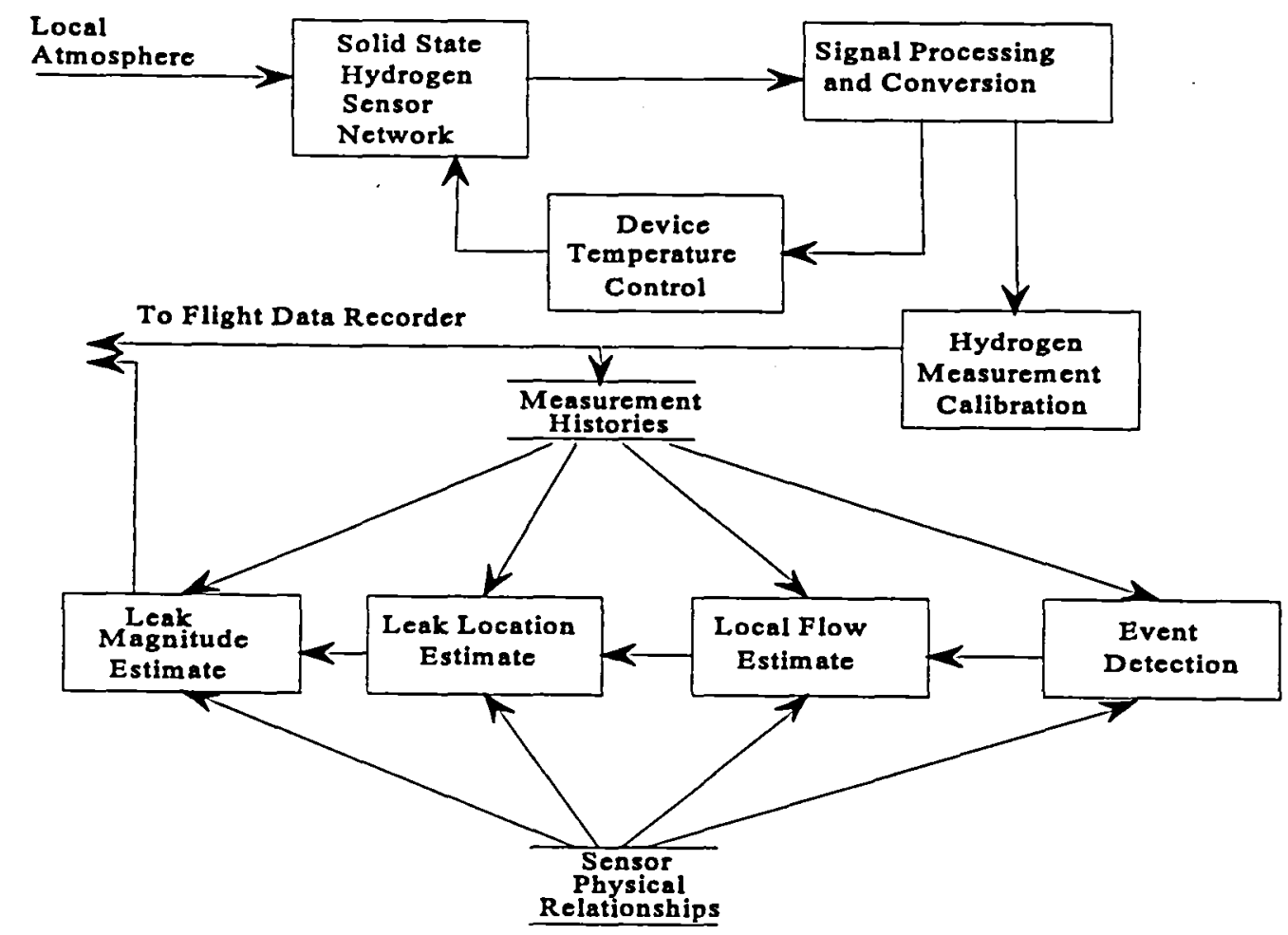

Figure 8. Flow diagram of the response of the detection system to the local atmosphere.

normalized to this value. The sensors have similar calibration curves over the range of concentrations from 50 PPM to $1 \%$ hydrogen. The similarity of the calibration curves is important since this means that processing of the sensor array response will only require a limited number of correction constants for each sensor rather than wholesale calibration curves for each sensor.

Examination of the dynamic responses in Figure 6 indicates the need to use the slope of the sensor response curve if an estimate of leak magnitude is required in less than one second. In previous literature, use has been made of the steady state response value that requires allowing the sensor to stabilize for relatively long periods of time at a fixed condition. ${ }^{3}$ This method not only makes calibration time consuming, but it is not relevant to a practical system for which the hydrogen levels may be rapidly time varying. We are studying various algorithms that allow hydrogen mixtures to be characterized by time derivatives or changes in the sensor responses. The difficulty is to find a technique that is simple enough to process in real time yet can be calibrated to the full range of conditions that a single sensor will encounter.

\section{Leak Detection Software and Algorithms}

The leak detection software consists of custom filter routines combined with rule-based expert systems and neural networks for fusing information from zone and site hydrogen sensors. The leak system output is a refined list of leak events characterized with prioritized potential leak locations, estimated amounts, and an optional leak plume visualization superimposed on a representative view of the fuel system components. The software modules are linked by an "executive system" to facilitate data flow and provide a graphical interface for the user. Heuristic rules based on sensor placement, propellant system configuration, and predominant convection are the basic algorithms for leak source identification and magnitude detection. Two neural network architectures are used in the system to rapidly identify leak locations after only a small number of data cycles for real-time applications. Figure 8 shows a general now diagram of the response of the detection system to the local atmosphere. 


\section{PROTOTYPE MULTIPOINT SYSTEM FOR REUSABLE LAUNCH VEHICLES}

Aerojet has developed a prototype leak detection system for Reusable Launch Vehicles (RLVs). ${ }^{8}$ The system consists of central microcontroller electronics, multiplexing electronics, and power conditioning electronics. Signal conditioning electronics located remotely with each sensor convert the reverse bias current into a 0-5 volt signal. The microcontroller is an Intel KC196 which can be configured with up to $\mathbf{5 1 2}$ Kbytes of EEPROM or SRAM for data storage. The microcontroller is designed with an Aerojet proprietary bus, which stacks with sensor interface boards and performs multiplexing tasks, and a power conditioning board. This system can be addressed through an RS-485 or RS-232 interface. Future flight system designs will add a MIL-STD 1553 digital bus for communications with vehicle and engine controllers.

The system can operate a large number of hydrogen sensors by using multiplexing techniques which allow several sensors to effectively share the same cable. The bias voltage is applied through a multiplexer to a number of active elements attached to the same line. The simultaneously active elements are differentiated by separate current sensors multiplexed to a common analog to digital (A/D) converter. By scanning the multiplexers, the output of all the sensors on the string can be converted in sequence.

Accurate hydrogen measurements require that the hydrogen sensor be maintained at a constant temperature $\left( \pm 0.5^{\circ} \mathrm{C}\right)$. Experience has shown that the optimal combination of response time and dynamic range of the CWRU diode sensor in this practical application is achieved with operating temperatures of 70-80 ${ }^{\circ} \mathrm{C}$. Active temperature control of each device is an option. However, feedback cabling and circuitry would have to be dedicated to each individual sensor. The approach which is used is to provide temperature control to all sensors and compensate in the software for the individual sensor temperature variations. A common heater voltage is applied to all devices in parallel. Early versions of the CWRU sensor had heater resistances which varied as much as $300 \%$. To achieve approximately equal device temperatures, device dependent trim resistors had to be added in series with the heater. Current sensors fabricated by CWRU have overcome the problem of variable heater resistance and variations of no more than $5 \%$ are routinely achieved.

Signal conditioning is performed at the sensor site to convert low level signals generated by the CWRU hydrogen and temperature sensor to high level signals for the centralized $A / D$ converter. Figure 9 shows the CWRU sensor mounted with a quad op-amp used for current to voltage conversion and voltage amplification. Aerojet and NASA MSFC are currently evaluating approaches for reducing the discrete circuitry on the sensor board into a single hybrid or ASIC. Options for these designs include the use of an onboard $A / D$ and simple digital interface. This approach is anticipated to significantly reduce the size of the sensor package and cabling.

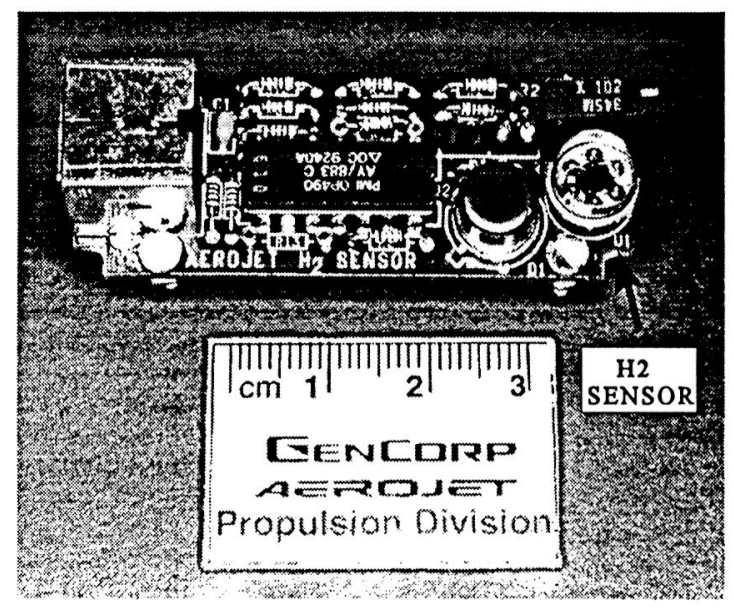

Figure 9. Hydrogen sensor mounted in signal conditioning hardware.

A flight prototype system has flown on the DC$X$ experimental vehicle. This system used eight hydrogen microsensors provided by Sandia National Laboratories for the flight tests. Aerojet and NASA MSFC are currently building a 32 sensor system for DC-XA flight tests in 1996. This flight system will consist of four electronic modules networked together enabling sensors to be distributed throughout the vehicle. The electronics used in the first prototype system have been adapted for the CWRU sensors and extended to Aerojet's commercial product design. A second generation of the Aerojet detection system using the CWRU 
hydrogen sensor design is currently being built by Aerojet for testing on the Technology Testbed Engine (TTBE) in later 1995. This system will use 16 sensors mounted directly to the Space Shuttle Main Engine (SSME) engine components in order to evaluate survivability and placement requirements for locating specific leak locations.

Aerojet has developed software to interface with the microcontroller data acquisition unit. This software was developed using National Instruments Lab Windows ${ }^{7}$ on a 486DX2/50 computer. The Lab Windows software has been used to provide the graphical user interface. Communications to the microcontroller are performed using custom "C" code and protocol developed in-house at Aerojet. Several screens are used in the software to facilitate setup, calibration, monitoring and analysis. During real-time monitoring, the raw signal values are converted to engineering units and displayed as both numerical displays and on a strip chart recorder. If any values exceed a pre-set threshold, a status light for the sensor is indicated and an audio alarm is sounded. The recorded data is stored to disk. Stored data can be recalled and displayed for analysis.

\section{COMMERCIAL HYDROGEN LEAK DETECTION SYSTEMS}

Aerojet has been pursuing several commercial applications for the CWRU hydrogen sensor technology. The first commercial product developed by Aerojet using the CWRU sensor is a system to detect hydrogen gas from pressurized fuel systems of dedicated natural gas vehicles. In response to air quality requirements of the 1990 Clean Air Act Amendments, the major automobile manufactures have started to produce vehicles which operate on natural gas. These vehicles use compressed natural gas stored at $\mathbf{3 0 0 0}$ psi on-board as fuel. To date, vehicles using natural gas have been converted from models which were originally equipped for gasoline. These vehicles, referred to as "conversions", have been produced in limited quantity. Leak checking of the full system has been done using conventional pressure decay and soap bubble techniques which can take hours to determine if leakage is below a typically acceptable level of $2.5 \mathrm{sccm} / \mathrm{hr}$. Production of natural gas vehicles in large volume in a traditional assembly line require that leak check operations of all critical joints be performed in less than 5 minutes per vehicle.

Aerojet has developed a leak check system for natural gas vehicles which can rapidly detect leaks when the fuel system is pressurized with $1 \% \mathrm{H}_{2} / 99 \% \mathrm{~N}_{2}$. The system consists of central microcontroller electronics described for the flight system, eight hydrogen sensors, and a host computer with graphical user interface and data analysis software as shown in Figure 10. The sensors are interfaced to a fuel line component using a flexible "boot" which surrounds the component such as a fitting. When the system is pressurized, a leak causes the detected hydrogen concentration in the boot to increase and is proportional to the leak rate. The quantitative leak rate is determined by calibration of the sensor boot to account for the free volume of the boot and any leakage of gas out of the boot. Ford Motor Company is the first commercial user of the Aerojet system. Several systems will be used in the production of Ford's 1996 model dedicated natural gas Crown Victoria vehicle.

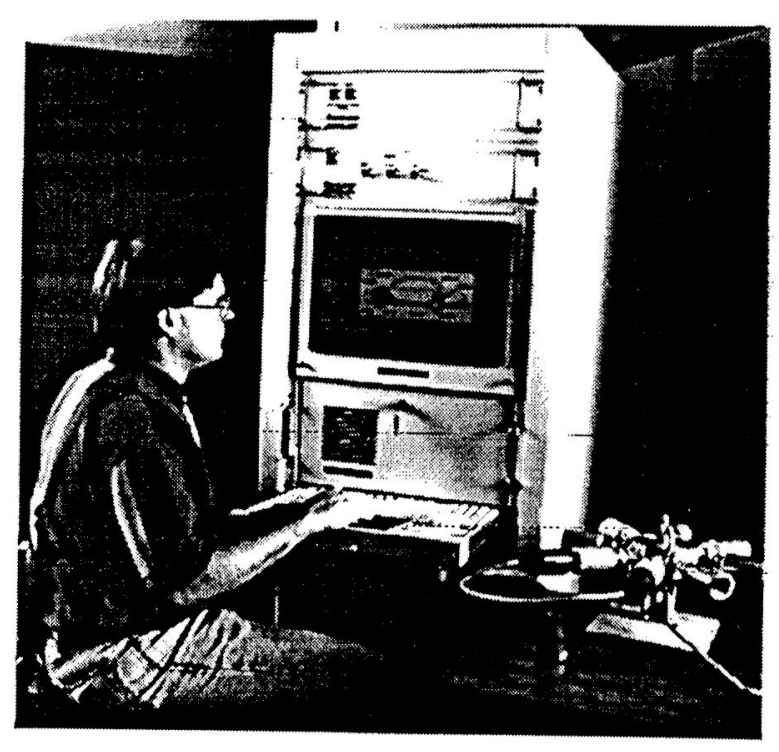

Figure 10. Leak monitoring system with visual display of leak location. The representation on the monitor is customized for automotive applications.

Other commercial applications for the CWRU hydrogen sensor technology are currently being explored. The present upper limit of sensor sensitivity of on the order of $5000 \mathrm{ppm}$ limits the use 
of the sensor. Within the current detection range is the detection of low level hydrogen releases from batteries and hydrogen fuel cells. As the electric vehicle industry expands, these applications may become more wide spread.

\section{CONCLUSIONS AND FUTURE PLANS}

The combined effort of government, academia, and industry has generated an integrated hydrogen leak monitoring system. A prototype automated, real-time, hydrogen propellant leak detection system has been developed for launch vehicle applications. The system consists of three elements: (1) a multiplexed sensor array, (2) a signal processing unit, and (3) diagnostic software. The system can monitor low concentrations of hydrogen and visually display the location and magnitude of the leak. A commercial system using the same elements has been developed for the automobile industry to leak check natural gas vehicles.

Continued improvement of the system is planned. NASA LeRC and CWRU are attempting to increase the detectable hydrogen concentration range of the hydrogen sensor to handle a wide range of applications. For example, hydrogen safety monitoring of facilities requires that the detection range of the CWRU sensor be increased to at least $40,000 \mathrm{ppm}$ (the lower explosive limit (LEL) of hydrogen in air) and be able to withstand exposure to $100 \%$ hydrogen. Later versions the sensor will be micromachined to decrease the sensor power consumption. Aerojet will continue to integrate the NASA LeRC and CWRU sensor into its system hardware with the objective of decreasing the size of the supporting hardware: A flight prototype system is being built for use on the Technology Test Bed Engine at NASA MSFC in 1995.

\section{ACKNOWLEDGMENTS}

Work performed by the authors at Aerojet was supported by a NASA/Marshall Space Flight Center Contract NAS8-39029. The authors would also like to gratefully acknowledge the helpful discussions with Dr. R. C. Hughes of Sandia National Laboratories, Dr. W. D. Williams and W. C. Nieberding of NASA LeRC. The technical assistance of Dak Knight of Calspan/NASA LeRC and Gaurav Bansal of NASA Lewis is also acknowledged. The contributions of Sandia National Laboratory in providing sensors for integration into the Aerojet hardware is also acknowledged.

\section{REFERENCES}

1. Hunter, Gary W.: A Survey and Analysis of Commercially Available Hydrogen Sensors, NASA Technical Memorandum 105878, November 1992.

2. Hunter, Gary W.: A Survey and Analysis of Experimental Hydrogen Sensors, NASA Technical Memorandum 106300, October 1992.

3. Lundstrom, I.; Armgarth M.; and Petersson, L.: Physics with Catalytic Metal Gate Chemical Sensors, CRC Critical Reviews in Solid State and Materials Sciences, Vol. 15, pp. 201-278, 1989.

4. Hughes, R. C.; Schubert, W. K.; Zipperian, T. E.; Rodriguez, J. L.; and Plut, T. A.: Thin Film Palladium and Silver Alloys and Layers for Metal-Insulator-Semiconductor Sensors, J. Appl. Phys., Vol. 62, pp. 1074-1038, 1987.

5. Hughes, R. C., Personal Communication.

6. Hunter, Gary W.; Neudeck, Phillip G.; Liu, C. C.; and Wu, Q. H.: Advances in Hydrogen

Sensor Technology at for Aerospace Applications, presented at the Advanced Earth-to-Orbit Propulsion Technology Conference, NASA George C. Marshall Space Flight Center, Huntsville, AL, May 1994.

7. National Instruments, Austin, TX.

8. Bickford, R. L.; Jansa, E. D.; Makel, D. B.; and Power, W. T.: Multipoint Hydrogen Propellant Leak Detection System, presented at the Advanced Earth-to-Orbit Propulsion Technology Conference, NASA George $C$. Marshall Space Flight Center, Huntsville, AL, May 1994. 


\begin{tabular}{|c|c|c|c|}
\hline \multicolumn{3}{|c|}{ REPORT DOCUMENTATION PAGE } & $\begin{array}{l}\text { Form Approved } \\
\text { OMB No. 0704-0188 }\end{array}$ \\
\hline \multicolumn{4}{|c|}{ 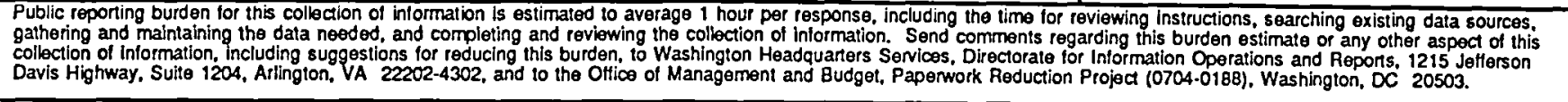 } \\
\hline 7. AGENCY USE ONLY (Leave blanK) & $\begin{array}{r}\text { 2. REPORT DATE } \\
\text { October } 1995\end{array}$ & \multicolumn{2}{|c|}{$\begin{array}{l}\text { 3. REPORT TYPE AND DATES COVERED } \\
\text { Technical Memorandum }\end{array}$} \\
\hline \multicolumn{3}{|c|}{$\begin{array}{l}\text { 4. TITLE AND SUBTTLE } \\
\text { A Hydrogen Leak Detection System for Aerospace and } \\
\text { Commercial Applications }\end{array}$} & 5. FUNDING NUMBERS \\
\hline \multicolumn{3}{|c|}{$\begin{array}{l}\text { 6. AUTHOR(S) } \\
\text { Gary W. Hunter, D.B. Makel, E.D. Jansa, G. Patterson, P.J. Cova, } \\
\text { C.C. Liu, Q.H. Wu, and W.T. Powers }\end{array}$} & WU-242-20-06 \\
\hline \multicolumn{3}{|c|}{$\begin{array}{l}\text { 7. PERFORMING ORGANIZATION NAME(S) AND ADDRESS(ES) } \\
\text { National Aeronautics and Space Administration } \\
\text { Lewis Research Center } \\
\text { Cleveland, Ohio } 44135-3191\end{array}$} & $\begin{array}{l}\text { FORMING ORGANIZATION } \\
\text { ORT NUMBER } \\
9924\end{array}$ \\
\hline \multicolumn{3}{|c|}{ 9. SPONSORING/MONITORING AGENCY NAME(S) AND ADDRESS(ES) } & $\begin{array}{l}\text { NSORING/MONITORING } \\
\text { ENCY REPORT NUMBER } \\
\text { SA TM-107063 } \\
\text { AA-95-2645 }\end{array}$ \\
\hline \multicolumn{4}{|c|}{$\begin{array}{l}\text { 11. SUPPLEMENTARY NOTES } \\
\text { Prepared for the 31st Joint Propulsion Conference and Exhibit cosponsored by AIAA, ASME, SAE, and ASEE, San Diego, California, } \\
\text { July 10-12, 1995. Gary W. Hunter, NASA Lewis Research Center; D.B. Makel, E.D. Jansa, G. Patterson, and P.J. Cova, GenCorp } \\
\text { Aerojet, Sacramento, California 95813; C.C. Liu and Q.H. Wu, Electronics Design Center, Case Western Reserve University, Cleveland, } \\
\text { Ohio 44106; W.T. Powers, NASA George C. Marshall Space Flight Center, Marshall Space Flight Center, Alabama 35812. Responsible } \\
\text { person, Gary W. Hunter, organization code 2510, (216) 433-6459. }\end{array}$} \\
\hline \multicolumn{3}{|c|}{$\begin{array}{l}\text { 12a. DISTRIBUTIONAVAILABILTY STATEMENT } \\
\text { Unclassified - Unlimited } \\
\text { Subject Category } 35 \\
\text { This publication is available from the NASA Center for Aerospace Information, (301) 621-0390. }\end{array}$} & . \\
\hline \multicolumn{4}{|c|}{$\begin{array}{l}\text { Leaks on the Space Shuttle while on the Launch Pad have generated interest in hydrogen leak monitoring technology. } \\
\text { Microfabricated hydrogen sensors are being fabricated at Case Western Reserve University (CWRU) and tested at NASA } \\
\text { Lewis Research Center (LeRC). These sensors have been integrated into hardware and software designed by Aerojet. This } \\
\text { complete system allows for multipoint leak monitoring designed to provide leak source and magnitude information in real } \\
\text { time. The monitoring system processes data from the hydrogen sensors and presents the operator with a visual indication } \\
\text { of the leak location and magnitude. Although the leak monitoring system was designed for hydrogen propulsion systems, } \\
\text { the possible applications of this monitoring system are wide ranged. This system is in operation in an automotive applica- } \\
\text { tion which requires high sensitivity to hydrogen. }\end{array}$} \\
\hline \multirow{2}{*}{\multicolumn{2}{|c|}{$\begin{array}{l}\text { 14. SUBJECT TERMS } \\
\text { Hydrogen; Leak; Detection }\end{array}$}} & & $\begin{array}{c}\text { 15. NUMBER OF PAGES } \\
13\end{array}$ \\
\hline & & & $\begin{array}{r}\text { 16. PRICE CODE } \\
\mathrm{A} 03\end{array}$ \\
\hline $\begin{array}{l}\text { 17. SECURTY CLASSIFICATION } \\
\text { OF REPORT } \\
\text { Unclassified }\end{array}$ & $\begin{array}{l}\text { 18. SECURTY CLASSIFICATION } \\
\text { OF THIS PAGE } \\
\text { Unclassified }\end{array}$ & $\begin{array}{l}\text { 19. SECURITY CLASSIFICATION } \\
\text { OF ABSTRACT } \\
\text { Unclassified }\end{array}$ & 20. LIMTTATION OF ABSTRACT \\
\hline NSN 7540-01-280-5500 & & & $\begin{array}{l}\text { andard Form } 298 \text { (Rev. 2-89) } \\
\text { sccitibed by ANSI Std. Z39-18 }\end{array}$ \\
\hline
\end{tabular}

